\title{
A systematic review of triage-related interventions to improve patient flow in emergency departments
}

Sven Oredsson ${ }^{*}$, Håkan Jonsson ${ }^{2}$, Jon Rognes ${ }^{3}$, Lars Lind ${ }^{4}$, Katarina E Göransson ${ }^{5,6}$, Anna Ehrenberg ${ }^{7}$, Kjell Asplund ${ }^{8}$, Maaret Castrén ${ }^{9}$ and Nasim Farrohknia ${ }^{10}$

\begin{abstract}
Background: Overcrowding in emergency departments is a worldwide problem. A systematic literature review was undertaken to scientifically explore which interventions improve patient flow in emergency departments.

Methods: A systematic literature search for flow processes in emergency departments was followed by assessment of relevance and methodological quality of each individual study fulfilling the inclusion criteria. Studies were excluded if they did not present data on waiting time, length of stay, patients leaving the emergency department without being seen or other flow parameters based on a nonselected material of patients. Only studies with a control group, either in a randomized controlled trial or in an observational study with historical controls, were included. For each intervention, the level of scientific evidence was rated according to the GRADE system, launched by a WHO-supported working group.
\end{abstract}

Results: The interventions were grouped into streaming, fast track, team triage, point-of-care testing (performing laboratory analysis in the emergency department), and nurse-requested $x$-ray. Thirty-three studies, including over 800,000 patients in total, were included. Scientific evidence on the effect of fast track on waiting time, length of stay, and left without being seen was moderately strong. The effect of team triage on left without being seen was relatively strong, but the evidence for all other interventions was limited or insufficient.

Conclusions: Introducing fast track for patients with less severe symptoms results in shorter waiting time, shorter length of stay, and fewer patients leaving without being seen. Team triage, with a physician in the team, will probably result in shorter waiting time and shorter length of stay and most likely in fewer patients leaving without being seen. There is only limited scientific evidence that streaming of patients into different tracks, performing laboratory analysis in the emergency department or having nurses to request certain $\mathrm{x}$-rays results in shorter waiting time and length of stay.

\section{Background}

Overcrowding in emergency departments (EDs) is an increasing global problem [1]. In the United States, an Institute of Medicine committee has characterized ED overcrowding as a national crisis [2]. Emergency department overcrowding also compromises patient safety and timeliness (time to appropriate treatment) [3], threatens

\footnotetext{
* Correspondence: sven.oredsson@skane.se 'Department of Emergency Medicine, Helsingborg Hospital, Helsingborg, Sweden

Full list of author information is available at the end of the article
}

patient privacy and confidentiality, and often leads to frustration among ED staff [4-12].

Multiple factors determine patient flow in EDs, $[13,14]$ and the input-throughput-output conceptual model has become an accepted approach toward understanding the causes of overcrowding $[3,15,16]$. According to the model, the causes may be sought in any of the three domains and actions to reduce overcrowding may be directed towards input, throughput or output from the ED. Although some of the suggested solutions to improve patient flow in EDs have arisen from systematic analyses, many improvements are of an ad hoc character [17]. Many of the new strategies
C Biomed Central

() 2011 Oredsson et al; licensee BioMed Central Ltd. This is an Open Access article distributed under the terms of the Creative Commons Attribution License (http://creativecommons.org/licenses/by/2.0), which permits unrestricted use, distribution, and reproduction in any medium, provided the original work is properly cited. 
are inspired by lean healthcare thinking with a focus on flow orientation, reduction in unnecessary work elements, continuous quality improvement, and participation of all co-workers [18-20].

Despite many efforts, scientific knowledge remains limited as regards which strategies and pragmatic approaches actually improve patient flow in EDs. The American Academy of Emergency Medicine recently released a statement concluding "it is currently unknown which strategies provide the best solution to fix throughput in the ED" [1].

In recent years, health authorities in many countries have introduced standards, with or without economic incentives, to decrease the length of stay in EDs [21]. The most well known is the 4-hour target set by the National Health Service (NHS) in the UK [22].

The objective of this review is to identify and evaluate the scientific evidence of various interventions to improve patient flow in EDs.

In 2010 The Swedish Council for Health Technology Assessment (SBU), a governmental agency, presented a systematic literature review to explore the scientific basis for various interventions to improve patient flow in EDs. The present review is based on data from this report [23].

\section{Methods}

A systematic search of the international literature published from 1966 through March 31, 2009 was performed in British Nursing Index, Business Source Premier, CINAHL, Cochrane Library, EMBASE, ProQuest ABI, PubMed, and Science Direct (for search strategies see additional file 1). The database search was complemented by a thorough review of reference lists and review articles. Inclusion of papers was limited to studies of adult patients ( $\geq 15$ years of age) visiting EDs for somatic reasons.

To be included, studies had to present data on waiting time (WT), i.e. the time interval between arrival at the ED and examination by a physician, length of stay (LOS), i.e. the total time spent in the ED, left without being seen (LWBS), i.e. the proportion of patients leaving the ED without being seen by a physician, or other flow parameters based on a nonselected material of patients. Studies were included only if they had a control group, either in a randomized controlled trial, or in an observational study with historical controls.

All studies were reviewed for quality by using validated checklists for internal validity, precision, and applicability (external validity) $[24,25]$. Methodological quality and clinical relevance of each study was graded as high, medium, or low. Two independent experts performed the review in a blinded manner and studies were only included if both experts considered the study as relevant.
To reduce variation between the experts, standardized forms were used.

The second step involved using the internationally developed GRADE system to achieve an overall appraisal of the scientific evidence upon which the report's conclusions are based [26]. The following factors were considered when appraising the overall strength of evidence: study quality, concordance/consistency, transferability/ relevance, precision of data, risk of publication bias, effect size, and dose-response. Predefined guidelines for up- and downgrading were used to arrive at the final grade indicating the strength of evidence [26]. Downgrading reflected limitations in study design or implementation, imprecision of estimates, variability in results, indirectness of evidence, or publication bias. Upgrading reflected a large magnitude of effect, a dose-response gradient, and consistency of data. Based on these rules, each conclusion was rated as having strong, moderately strong, limited, or insufficient scientific evidence. In the grading process, studies having low quality and relevance were included when studies of medium quality and relevance were not available.

\section{Results}

Literature search, selection process, and outcome measures

The initial search identified 1,218 abstracts, which were evaluated for relevance. Fifty-four articles were considered as potentially relevant and evaluated in full text. In addition, 36 articles were found by "snowballing", i.e. through reference lists and other sources. Ultimately, 33 articles were selected. The final selection was based on relevance, eligibility, and study design (Figure 1). Of these articles, none fulfilled the criteria for high quality, 22 were of medium quality, and 11 were of low quality.

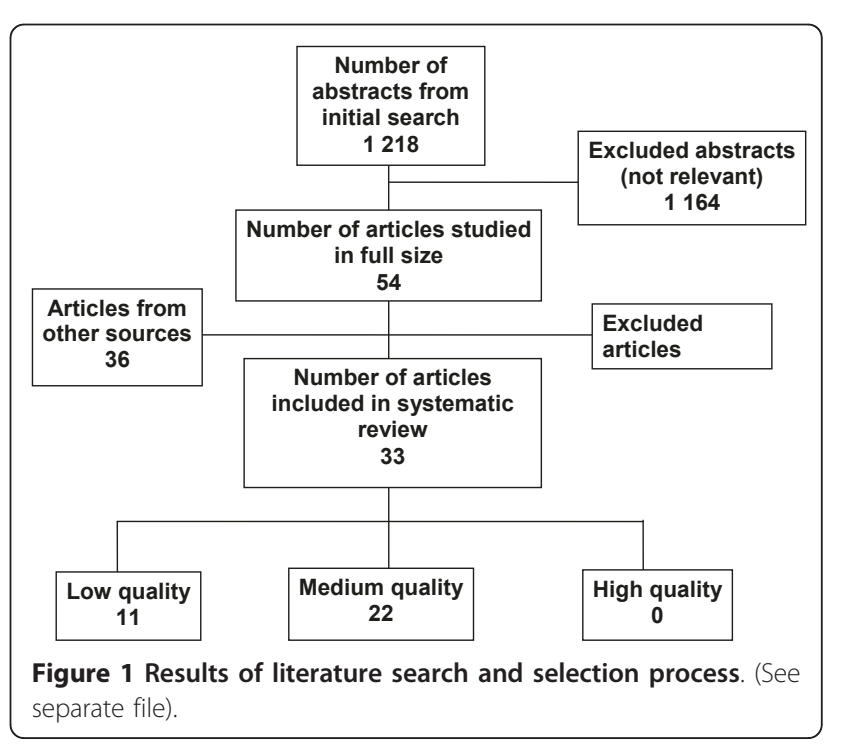


The two most common outcome measures were WT (16 studies) and LOS (23 studies). Less common (11 studies) were reports on LWBS. Notably, none of the studies reported on indicators of patient safety or cost benefit.

The articles that were finally selected were divided into five groups, each group representing a specific type of intervention used to improve patient flow in the ED. The interventions are: streaming, fast track, team triage, point-of-care testing, and nurse-requested x-ray.

\section{Streaming}

Streaming refers to routines where patients, following triage or brief evaluation, are divided into different processes (streams) according to more or less defined criteria. The most common example of streaming involves the use of a separate process, usually called fast track, to handle patients with less serious symptoms. Of the 16 studies on streaming that fulfilled the inclusion criteria [27-42], 13 focused on fast track and are reported separately (see below). The three remaining studies were of medium quality. Two of these studies separated patients into two processes (streams); patients who would benefit from admission and those who could be treated as outpatients $[40,41]$. The cohorts were large; 63,000 and 99,000 patients, respectively. King et al were unable to demonstrate shorter WT. However, LOS in the ED was reduced in both streams. Kelly et al reported reduced WT and shorter LOS for patients in 2 of 5 triage levels. The ED was also able to fulfil a 4-hour goal of WT to a greater extent with than without streaming. The third study divided patients of all categories into two streams where patients were cared for by two teams of physicians and nurses [42]. The method was called "team assignment" and reduced WT by 9 minutes on average, and the number of patients that left without being seen was reduced from $2.3 \%$ to $1.6 \%$ (Additional file 2).

Based on these studies, the scientific evidence for streaming, not including fast track, is limited (Table 1).

\section{Fast track}

Thirteen studies described the effects of fast track on patient flow in the ED [27-39]. Two of the studies were quasi-randomized, whereas the rest were prospective studies with historical (retrospective) control groups. Of the 13 studies, 9 were of medium quality and 4 were of low quality (Additional file 3).

Kilic et al published a quasi-randomized study where fast track was used every second day during daytime for 1 month [34]. During days without fast track, suitable patients were registered and used as controls. The study was relatively small with 143 patients in the study group and 126 patients in the control group. WT was significantly reduced with fast track.

A study in New Zealand evaluated and treated patients with less complicated problems via a separate process named the Rapid Assessment Clinic (RAC) during odd weeks [33]. Sixteen percent of all patients were selected to RAC. WT and LOS were reduced for patients in triage levels 4 and 5 . The study indicated no effect on patients in the other triage levels.

In 2008, an Australian cohort study with 20,000 patients in each group (with or without fast track) demonstrated significantly shorter WT with fast track [30].

Another Australian study selected 33\% of all patients to be treated by a senior physician in a fast track model [38]. WT was reduced, and the number of patients that left the ED without being seen dropped by $50 \%$.

In a third study from Australia, O'Brien et al demonstrated reduced WT by $20 \%$ and reduced LOS by $18 \%$ for nonadmitted, fast track patients [35]. For patients that were eventually admitted, WT and LOS in the ED remained unchanged.

The largest study, an observational study originating from Spain, compared 71,000 fast track patients with an equally large control group [36]. Despite a $4.4 \%$ increase in attendance during the fast track period, WT was $50 \%$ shorter and LOS $10 \%$ shorter for the total patient population, when fast track was introduced. In this study, physician assistants and nurse practitioners staffed the fast track.

Another seven smaller studies also demonstrated significant effects of fast track (Additionel file 3).

In conclusion, all 13 studies demonstrated positive effects on WT and LOS when fast track was implemented. Based on these studies, the scientific evidence for improved patient flow following the implementation of fast track is moderately strong (Table 2).

Table 1 Evaluation of scientific evidence of streaming according to GRADE

\begin{tabular}{llllll}
\hline $\begin{array}{l}\text { Outcome } \\
\text { measures }\end{array}$ & $\begin{array}{l}\text { Number of patients } \\
\text { (number of studies) }\end{array}$ & Study design & $\begin{array}{l}\text { Outcome*, } \\
\text { median } \\
\text { (min-max) }\end{array}$ & $\begin{array}{l}\text { Scientific evidence } \\
\text { according to GRADE }\end{array}$ & Comments \\
\hline $\begin{array}{l}\text { Waiting time } \\
\text { (shorter) }\end{array}$ & $\begin{array}{l}240429 \\
\text { (3 studies) }\end{array}$ & $\begin{array}{l}\text { Observational } \\
\text { studies }\end{array}$ & $31(14-48)$ min & Limited & Upgraded because of study quality. \\
$\begin{array}{l}\text { Length of } \\
\text { stay (shorter) }\end{array}$ & (2 studies) & $\begin{array}{l}\text { Observational } \\
\text { studies }\end{array}$ & $9.5(0-11)$ min & Limited & Downgraded because of outcome size \\
\hline
\end{tabular}

* Outcome calculated as the difference between intervention and control 
Table 2 Evaluation of scientific evidence of fast track according to GRADE

\begin{tabular}{|c|c|c|c|c|c|}
\hline Outcome measures & $\begin{array}{l}\text { Number of patients } \\
\text { (number of studies) }\end{array}$ & $\begin{array}{l}\text { Study } \\
\text { design }\end{array}$ & $\begin{array}{l}\text { Outcome*, } \\
\text { median } \\
\text { (min-max) }\end{array}$ & $\begin{array}{l}\text { Scientific } \\
\text { evidence } \\
\text { according } \\
\text { to GRADE }\end{array}$ & Comments \\
\hline $\begin{array}{l}\text { Waiting time } \\
\text { (shorter) }\end{array}$ & $\begin{array}{l}>90000 \\
\text { (9 studies) }\end{array}$ & $\begin{array}{l}1 \text { RCT } \\
8 \\
\text { observational } \\
\text { studies }\end{array}$ & $24.5(2-51) \mathrm{min}$ & $\begin{array}{l}\text { Moderately } \\
\text { strong } \\
\oplus \oplus \oplus\end{array}$ & $\begin{array}{l}\text { Upgraded because of outcome size } \\
\text { and concordance of data }\end{array}$ \\
\hline Length of stay (shorter) & $\begin{array}{l}>100000 \\
\text { (10 studies) }\end{array}$ & $\begin{array}{l}2 \mathrm{RCT} \\
8 \\
\text { observational } \\
\text { studies }\end{array}$ & $27(4-74) \min$ & $\begin{array}{l}\text { Moderately } \\
\text { strong } \\
\oplus \oplus \oplus\end{array}$ & $\begin{array}{l}\text { Upgraded because of outcome size } \\
\text { and concordance of data }\end{array}$ \\
\hline $\begin{array}{l}\text { Number of patients leaving ED } \\
\text { without being seen by a physician } \\
\text { (fewer) }\end{array}$ & $\begin{array}{l}>90000 \\
\text { (5 studies) }\end{array}$ & $\begin{array}{l}\text { No RCT } \\
5 \\
\text { observational } \\
\text { studies }\end{array}$ & $\begin{array}{l}3.1(0.2-4.1) \\
\text { percent }\end{array}$ & $\begin{array}{l}\text { Moderately } \\
\text { strong } \\
\oplus \oplus \oplus\end{array}$ & $\begin{array}{l}\text { Upgraded because of outcome size } \\
\text { and concordance of data }\end{array}$ \\
\hline Patient satisfaction (increased) & $\begin{array}{l}447 \\
\text { (2 studies) }\end{array}$ & $\begin{array}{l}1 \text { RCT } \\
1 \\
\text { observational } \\
\text { study }\end{array}$ & - & $\begin{array}{l}\text { Insufficient } \\
\oplus\end{array}$ & $\begin{array}{l}\text { Downgraded because of study } \\
\text { quality, imprecise data and low } \\
\text { reproducibility }\end{array}$ \\
\hline
\end{tabular}

* Outcome calculated as the difference between intervention and control for all patients or for patients leaving the ED if data is missing for all patients. If results only are presented per triage group calculations are made for triage group 4.

\section{Team triage}

Team triage is defined as triage handled by a team that includes a physician. The rationale for team triage is to increase accuracy and efficiency in the initial process of patient evaluation. Six articles on team triage were included and reviewed, of which three were of medium quality and three were of low quality (Additional file 4) [43-48]. Two studies were quasi-randomized, and the remainders were prospective observational studies with retrospective controls.

A quasi-randomized study from Canada with 6,000 patients evaluated the effect of a triage liaison physician on LOS and LWBS [43]. The liaison physician facilitated patient flow by supporting the triage nurse, evaluating ambulance patients, initiating the diagnostic procedure, and handling administrative questions. Total LOS was reduced by $11 \%$ and LWBS was reduced by $20 \%$.

In a study from Northern Ireland, Subash et al randomized approximately 1,000 patients to team triage or ordinary triage [44]. WT to see a physician was statistically reduced, as was the waiting time to $\mathrm{x}$-ray. However, no reduction in total LOS could be demonstrated.

In a study from the United States, Partovi et al investigated the effect of a senior emergency physician in the triage team and reported that total LOS decreased by 82 minutes on average [47]. Using multivariate analysis, they showed that the effect was mainly the result of team triage, whether or not the patient was admitted, and whether or not x-ray was needed.

An Australian study with over 10,000 patients evaluated the effect of a Rapid Assessment Team (RAT) consisting of a physician and a registered nurse [48]. The
WT targets were achieved in 59\% with RAT, compared to $39 \%$ without RAT.

Based on the reviewed studies, we conclude that limited evidence suggests an effect of team triage on patient flow as measured by WT and LOS. However, relatively strong evidence suggests that team triage reduces the number of patients leaving the ED without being seen by a physician (Table 3 ).

\section{Point-of-care testing}

Point-of-care testing (POCT), which in this review refers to moving laboratory analysis to the ED, has been introduced by some hospitals to increase the speed of diagnosis in the ED. Six studies of POCT fulfilled the inclusion criteria [49-54]. Four of these studies were classified as medium quality and two as low quality (Additional file 5).

A randomized study from Canada demonstrated shorter LOS when laboratory analyses were performed at the ED, especially for nonadmitted patients [50]. However, the study was small and therefore had low statistical power. Another randomized study with 800 patients demonstrated significant changes in management, but no effect on LOS or admission rates [49].

In a US study, Lee-Lewandrowski et al found shorter turnaround time (i.e. the time from ordering laboratory tests to the results being available for the attending physician) and shorter LOS with POCT [51]. The study demonstrated high satisfaction among the staff.

The selection of laboratory tests available as POCT has a substantial impact on the results. In a US study by Parvin et al, almost $95 \%$ of the patients also needed central 
Table 3 Evaluation of scientific evidence of team triage according to GRADE

\begin{tabular}{|c|c|c|c|c|c|}
\hline Outcome measures & $\begin{array}{l}\text { Number of patients } \\
\text { (number of studies) }\end{array}$ & Study design & $\begin{array}{l}\text { Outcome*, median } \\
\text { (min-max) }\end{array}$ & $\begin{array}{l}\text { Scientific } \\
\text { evidence } \\
\text { according to } \\
\text { GRADE }\end{array}$ & Comments \\
\hline $\begin{array}{l}\text { Number of patients leaving } \\
\text { ED without being seen by a } \\
\text { physician (fewer) }\end{array}$ & $\begin{array}{l}32830 \\
\text { (4 studies) }\end{array}$ & $\begin{array}{l}1 \text { RCT } \\
3 \text { observational } \\
\text { studies }\end{array}$ & 1.3 (1.2-6.8) percent & $\begin{array}{l}\text { Moderately } \\
\text { strong } \\
\oplus \oplus \oplus\end{array}$ & $\begin{array}{l}\text { Upgraded because of } \\
\text { concordance of data }\end{array}$ \\
\hline $\begin{array}{l}\text { Waiting time } \\
\text { (shorter) }\end{array}$ & $\begin{array}{l}25927 \\
\text { (3 studies) }\end{array}$ & $\begin{array}{l}\text { No RCT } \\
3 \text { observational } \\
\text { studies }\end{array}$ & $18(16-20) \mathrm{min}$ & $\begin{array}{l}\text { Limited } \\
\oplus \oplus\end{array}$ & $\begin{array}{l}\text { Downgraded because of study } \\
\text { quality and heterogeneity }\end{array}$ \\
\hline Length of stay (shorter) & $\begin{array}{l}29674 \\
\text { (4 studies) }\end{array}$ & $\begin{array}{l}2 \mathrm{RCT} \\
2 \text { observational } \\
\text { studies }\end{array}$ & $40.5(0-55) \mathrm{min}$ & $\begin{array}{l}\text { Limited } \\
\oplus \oplus\end{array}$ & $\begin{array}{l}\text { Upgraded because of } \\
\text { outcome size. Downgraded } \\
\text { because of study quality. }\end{array}$ \\
\hline
\end{tabular}

* Outcome calculated as the difference between intervention and control

laboratory analyses to complement POCT. Consequently, POCT had no effect on the patients' length of stay [52].

Based on the studies assessed, the effect of POCT on turnaround time is supported by relatively strong evidence, whereas its effect on LOS is supported by only limited evidence (Table 4).

\section{Nurse-requested $x$-ray}

$\mathrm{X}$-ray examination is another time-consuming process in the ED. To shorten waiting time, some hospitals have piloted a routine of nurse-requested $x$-ray. Of the three studies on nurse-requested $\mathrm{x}$-ray that were included in this review, two were of medium quality and one was of low quality. All studies were randomized, in one case quasi-randomized (Additional file 6) [55-57].

In a British study including 1,800 patients, registered nurses could request $\mathrm{x}$-ray examinations of injuries below the elbow and knee [57]. No specific training was given the nurses, and patients were separated by a triage nurse to nurse first or doctor first. In the group seen first by a nurse, LOS was reduced for patients that did not need an x-ray, whereas no difference was observed in the group needing an $\mathrm{x}$-ray. Nurses ordered slightly more $\mathrm{x}$-rays $(4 \%)$ than physicians did.
In a study by Lindley-Jones et al, also performed in the UK, a triage nurse randomized orthopedic patients with suspected fracture to nurse request or doctor or nurse practitioner request [55]. Time to diagnosis was significantly shorter in the nurse request group. However, nearly $8 \%$ of patients that did not receive a nurserequested $\mathrm{x}$-ray did receive an $\mathrm{x}$-ray following the physician's examination.

In a quasi-randomized study from Australia, a triage nurse requested $\mathrm{x}$-rays on odd dates and a physician made the request on even dates [56]. The study included only patients with wrist or ankle injuries. The study reported no difference in LOS in the ED between the groups.

Based on these studies, the scientific evidence for shorter WT and/or LOS following nurse-requested $\mathrm{x}$ ray was graded as limited (Table 5).

\section{Discussion}

Of the five interventions addressed in this review, fast track demonstrates the best scientific evidence. In addition to improving patient flow, fast track would likely have benefits related to economics and patient satisfaction. However, this requires further evaluation. Concerning ethics and patient safety, it is important to note that

Table 4 Evaluation of scientific evidence of point of care testing according to GRADE

\begin{tabular}{|c|c|c|c|c|c|}
\hline $\begin{array}{l}\text { Outcome } \\
\text { measures }\end{array}$ & $\begin{array}{l}\text { Number of patients } \\
\text { (number of studies) }\end{array}$ & $\begin{array}{l}\text { Study } \\
\text { design }\end{array}$ & $\begin{array}{l}\text { Outcome*, median } \\
\text { (min-max) }\end{array}$ & $\begin{array}{l}\text { Scientific evidence } \\
\text { according to GRADE }\end{array}$ & Comments \\
\hline $\begin{array}{l}\text { Response } \\
\text { time } \\
\text { (shorter) }\end{array}$ & $\begin{array}{l}12273 \\
\text { (3 studies) }\end{array}$ & $\begin{array}{l}\text { No RCT } \\
3 \\
\text { observational } \\
\text { studies }\end{array}$ & $51(51-51) \min$ & $\begin{array}{l}\text { Moderately strong } \\
\oplus \oplus \oplus\end{array}$ & $\begin{array}{l}\text { Downgraded because of study quality. } \\
\text { Upgraded because of outcome size. }\end{array}$ \\
\hline $\begin{array}{l}\text { Length of } \\
\text { stay } \\
\text { (shorter) }\end{array}$ & $\begin{array}{l}18401 \\
\text { (5 studies) }\end{array}$ & $\begin{array}{l}2 \text { RCT } \\
3 \\
\text { observational } \\
\text { studies }\end{array}$ & $21(-8-54) \min$ & $\begin{array}{l}\text { Limited } \\
\oplus \oplus\end{array}$ & $\begin{array}{l}\text { Downgraded because of low } \\
\text { reproducibility and heterogeneity }\end{array}$ \\
\hline
\end{tabular}

* Outcome calculated as the difference between intervention and control 
Table 5 Evaluation of scientific evidence of nurse-requested $x$-ray according to GRADE

\begin{tabular}{|c|c|c|c|c|c|}
\hline $\begin{array}{l}\text { Outcome } \\
\text { measures }\end{array}$ & $\begin{array}{l}\text { Number of patients } \\
\text { (number of studies) }\end{array}$ & $\begin{array}{l}\text { Study } \\
\text { design }\end{array}$ & $\begin{array}{l}\text { Outcome*, median } \\
\text { (min-max) }\end{array}$ & $\begin{array}{l}\text { Scientific evidence } \\
\text { according to GRADE }\end{array}$ & Comments \\
\hline $\begin{array}{l}\text { Waiting time and/ } \\
\text { or length of stay } \\
\text { (shorter) }\end{array}$ & $\begin{array}{l}2682 \\
3 \text { studies }\end{array}$ & $\mathrm{RCT}$ & $\begin{array}{l}10(6-37) \\
\min \end{array}$ & $\begin{array}{l}\text { Limited } \\
\oplus \oplus\end{array}$ & $\begin{array}{l}\text { Downgraded because of study quality, } \\
\text { low reproducibility and heterogeneity }\end{array}$ \\
\hline
\end{tabular}

many studies clearly demonstrate that the introduction of fast track does not negatively affect treatment and waiting times of patients with more severe diseases and injuries. However, none of the studies in this review have evaluated patient safety outcome measures, e.g. mortality and need for treatment in an intensive care unit.

Fast track for patients with uncomplicated diseases and injuries was introduced and evaluated in EDs of many countries already in the 1990s [58]. The main intention of fast track was to reduce the total number of patients staying in the ED, and thereby improve patient satisfaction and patient safety. Patients were usually selected for fast track based on the triage nurse's decision of appropriateness. Many hospitals have developed their own rules and inclusion criteria for fast track, e.g. superficial wounds, less severe allergic reactions, fractures and distortions of small joints and bones, dog and cat bites, and minor burns $[25,34,37]$. The proportion of patients suitable for fast track varies between $10 \%$ and $30 \%$ of total patients seen in the ED $[27,33,35]$. For practical reasons, fast track is usually in operation during peak hours, i.e. not during nights.

Some studies have serious limitations resulting from wide variations in staffing and patient selection. However, when triage levels and selection routines are clearly specified, the strength of the data in many studies is satisfactory.

In many countries, it has become increasingly common to refer patients with uncomplicated problems to primary care facilities outside the hospital [59-61]. Although such an approach can be tempting as an alternative to fast track, it raises warning signals about patient safety and patient satisfaction [62].

Some authors stress the importance of using a senior physician to staff the fast track [38]. Other studies, however, demonstrate positive effects when junior doctors [27] are engaged and when nurse practitioners manage fast track [31]. Hence, it is likely that the concept rather than the seniority of staffing plays a decisive role. Many authors emphasize correct patient selection [28,34,37]. Patients selected for fast track should be able to manage without too many diagnostic procedures, e.g. laboratory tests and $\mathrm{x}$-rays. Another important factor involves directing fast track patients to specific areas in the ED, separate from areas where patients with higher medical priorities are managed.

Streaming of patients on the basis of presumed hospital admission did not appear to improve patient flow. Reduced WT and LOS were detected only among patients that could be discharged, which is in line with the positive results of fast track. Few relevant studies have been published on streaming other than fast track, limiting the chances of detecting strong evidence.

In Sweden, there has been a recent development of triage systems that combine streaming into different processes with refined triage scales based on vital signs and precise symptoms $[63,64]$. The rationale for these new systems of process triage has been to improve patient flow and to increase patient safety, but this has yet to be verified in published studies.

Although team triage has not been universally defined, it usually means that a team consisting of a physician and a nurse initially evaluates the patient. In some instances a receptionist or a nurse assistant complements the team. Team duties vary. To avoid "bottle necks" it is important that the total handling time per patient is short, which indirectly defines the tasks of the team. With a physician present in the team, it has become increasingly common to add procedures, e.g. ordering laboratory tests and $\mathrm{x}$-rays. In some studies, patients with minor complaints receive final treatment from the team, similar to the principle of fast track. Most authors agree that the team should focus on initiating and planning patient treatment, whereas final treatment should be referred to the ordinary staff. The advantage of team triage may be most significant in complex situations, whereas noncomplex patients are better handled by fast track. Most authors emphasize the importance of a senior physician in team triage $[44,45]$. Working as a team also offers educational and training opportunities for inexperienced staff [46].

The main effect of team triage appears to be that fewer patients leave the ED without being seen by a physician. Such an effect is not surprising given the presence of a physician in the triage team. However, it is also an indirect effect of handling patients more rapidly, which in turn could benefit patient safety.

More than two thirds of all patients seeking help at an ED require laboratory tests [14]. The process of laboratory testing is usually complex and includes different 
steps, e.g. ordering, sampling, marking, transportation, analysis, reporting of results, interpretation, and informing the patient. A Belgian study reports that the process adds approximately 80 minutes to the LOS in the ED [65]. Several interventions have been applied to shorten the process of laboratory testing, e.g. early ordering, predefined test panels based on symptoms and/or suspected diagnosis, limitations on tests that can be ordered from the ED, faster transportation to the laboratory, and faster reporting systems. Point-of-care-testing (POCT), which involves moving analytical instruments to the ED, has also been suggested.

Introducing POCT to the ED significantly decreases turnaround time for the laboratory analyses that can be performed as POCT. The effect on WT and LOS depends on the range of tests that can be analyzed. As a consequence of technical advancements, the range of tests continues to expand, and thus the positive effect on LOS can be expected to increase in the future. In this process, it is essential to consider and evaluate the precision and reliability of the methods [66]. Low precision will affect patient safety and hamper the effects on flow - at least in the long-term.

$\mathrm{X}$-ray examination is another time-consuming process in the ED. In many cases, it is evident at first presentation that the patient needs an $\mathrm{x}$-ray. This has led to the routine of nurse-requested $x$-ray in many EDs. The routine is usually limited to $x$-ray of distal joints and bones in the hand, foot, wrist, and ankle [55-57].

One could expect that requesting $\mathrm{x}$-ray examination early might reduce LOS. However, none of the included studies demonstrated such an effect. On the negative side of nurse-requested $\mathrm{x}$-ray is the increased risk of needing additional $\mathrm{x}$-rays following the physician's examination. This could probably be reduced by greater emphasis on education [55-57]. One of the studies [57] demonstrated shorter LOS for patients not needing $\mathrm{x}$-ray, which again suggests that sorting out patients that require no further investigation has the greatest impact on patient flow [45].

There are some important limitations of this review. Some of the interventions influence the entire process, i.e. team triage, fast track, and other forms of streaming, while others affect only certain parts of the process, i.e. POCT and nurse-requested $\mathrm{x}$-ray.

Fast track is the most studied intervention and the method supported by the strongest scientific evidence. However, it is reasonable to perceive additive, perhaps synergetic, effects between all of the interventions described in this review, and a broad approach is most likely the way to success. This is in line with lean thinking, comprising continuous improvement in all parts of the process $[18,67]$. As the process relies heavily on technology and human interaction, extensive staff involvement is essential.
Processes in the ED are interlaced and coherent with processes before and after the ED stay. Prehospital and primary care are examples of processes before, and the provision of hospital beds is an example of a process after the ED visit. Therefore, processes outside of the ED setting also need to be systematically reviewed and improved.

Finally, one must acknowledge the design limitations in many of the studies in this review. It is difficult to isolate the effect of an intervention when organizational issues interfere. Context-related factors and organizational placebo effects can play a stronger role than the intervention itself, often making it difficult to draw conclusions. The effects of different interventions are hard to isolate and depend on the local context. This calls for additional methodological approaches with sharper focus on underlying factors. Interventions may also have consequences on quality, patient and staff satisfaction, and economic and ethical issues, all of which must be taken into consideration. Consequently, further studies and new approaches are needed to fully evaluate the effects of organizational interventions.

\section{Conclusions}

Introducing fast track for patients with less severe symptoms results in shorter waiting time, shorter length of stay, and fewer patients leaving without being seen. Team triage, with a physician in the team, will probably result in shorter waiting time and shorter length of stay and most likely in fewer patients leaving without being seen. There is only limited scientific evidence that streaming of patients into different tracks, performing laboratory analysis in the emergency department or having nurses to request certain $\mathrm{x}$-rays results in shorter waiting time or length of stay.

\section{Additional material}

\section{Additional file 1: Search strategies.}

Additional file 2: Streaming. (Detailed analysis of reference [40-42]).

Additional file 3: Fast track. (Detailed analysis of reference [27-39].

Additional file 4: Team triage and similar interventions. (Detailed analysis of reference [43-48]).

Additional file 5: Point-of-care testing. (Detailed analysis of reference [49-54]).

Additional file 6: Nurse-requested x-ray. (Detailed analysis of reference [55-57]).

\section{Author details}

'Department of Emergency Medicine, Helsingborg Hospital, Helsingborg, Sweden. ${ }^{2}$ Department of Orthopedics, Uppsala University Hospital, Uppsala, Sweden. ${ }^{3}$ Department of Management and Organisation, Stockholm School of Economics, Stockholm, Sweden. ${ }^{4}$ Department of Medicine, Uppsala University Hospital, Uppsala, Sweden. ${ }^{5}$ Department of Emergency Medicine, 
Karolinska University Hospital, Solna, Sweden. ${ }^{6}$ Department of Medicine, Karolinska Institutet, Solna, Sweden. ${ }^{7}$ School of Health and Social Studies, Dalarna University, Falun, Sweden. ${ }^{8}$ Department of Public Health and Clinical Medicine, University Hospital, Umeå, Sweden. ${ }^{9}$ Department of Clinical Science and Education and Section of Emergency Medicine, Södersjukhuset (Stockholm South General Hospital), Stockholm, Sweden. ${ }^{10}$ Department of Emergency Medicine, Uppsala University Hospital, Uppsala, Sweden.

\section{Authors' contributions}

All authors participated in the design of the review. $\mathrm{SO}$ and $\mathrm{HJ}$ performed the analysis of the literature. All authors were part of conclusions and final grading. SO drafted the manuscript and all authors read and approved the final manuscript.

\section{Competing interests}

The authors declare that they have no competing interests.

Received: 10 April 2011 Accepted: 19 July 2011 Published: 19 July 2011

\section{References}

1. Eitel DR, Rudkin SE, Malvehy MA, Killeen JP, Pines JM: Improving service quality by understanding emergency department flow: a White Paper and position statement prepared for the American Academy of Emergency Medicine. J Emerg Med 2010, 38(1):70-9.

2. Institute of Medicine Committee on the Future of Emergency Care in the US Health System: The future of emergency care in the United States health system. Ann Emerg Med 2006, 48:115-20.

3. Bernstein SL, D'Onofrio G: Public health in the emergency department: Academic Emergency Medicine consensus conference executive summary. Acad Emerg Med 2009, 16:1037-9.

4. Moskop JC, Sklar DP, Geiderman JM, Schears RM, Bookman KJ: Emergency department crowding, part 1-concept, causes, and moral consequences. Ann Emerg Med 2009, 53:605-11.

5. Trout A, Magnusson AR, Hedges JR: Patient satisfaction investigations and the emergency department. Acad Emerg Med 2000, 7:695-709.

6. Vieth $\mathrm{TL}$, Rhodes $\mathrm{KV}$ : The effect of crowding on access and quality in an academic ED. Am J Emerg Med 2006, 24:787-94.

7. Derlet RW, Richards JR: Overcrowding in the nations emergency departments: complex causes and disturbing effects. Ann Emerg Med 2000, 35:63-8.

8. Magalski AE, Benenson RS, Cavanaugh SH, Williams ED: A pneumonia clinical pathway decreases time to antibiotic treatment, length of stay and mortality. Acad Emerg Med 1999, 6:1243-8.

9. Erickson C, McErlean M, Bartfield J, Verdile V: Relationship between maloccurrence and ED census and staffing. Acad Emerg Med 2001, 8:499.

10. Ciesielski G, Clark N: Safety in the emergency department: it's about time. Kans Nurse 2007, 82:3-6.

11. Miro O, Antonio MJ, Jimenez S, De Dios A, Sanchez M, Borras A, Millá J: Decreased health care quality associated with emergency department overcrowding. Eur J Emerg Med 1999, 6:105-7.

12. Pearce L: Complete turnaround Tears, long trolley waits and a hostile local press characterised A\&E in Bath. Nurs Stand 2002, 16:16-7.

13. Walley P: Designing the accident and emergency system: Lessons from manufacturing. Emerg Med J 2003, 20:126-30.

14. Yoon P, Steiner I, Reinhardt G: Analysis of factors influencing length of stay in the emergency department. Can J Emerg Med 2003, 5:155-61.

15. Rotstein Z, Wilf-Miron R, Lavi B: The dynamics of patient visits to a public hospital ED: a statistical model. Am J Emerg Med 1997, 15:596-9.

16. Green LV, Kolesar PJ: On the validity and utility of queuing models of human service. Ann Op Res 1987, 9:469-79.

17. Harvey M, Al Shaar M, Cave G, Wallace M, Brydon P: Correlation of physician seniority with increased emergency department efficiency during a resident doctors'strike. N Z Med J 2008, 121:59-68.

18. Åhlström P: Lean service operations: translating lean production principles to service operations. Int I Serv Tech Manag 2004, 5:545.

19. George M, Rolands D, Kastle B: What is Lean Six Sigma? New York: McGrawHill; 2004.

20. de Koning H, Verver JPS, van den Heuvel J, Bisgaard S, Does RJ: Lean six sigma in healthcare. J Helathcare Qual 2006, 28(2):4-11.

21. Horwitz LI, Green J, Bradley EH: US emergency department performance on wait time and length of visit. Ann Emerg Med 2010, 55(2):133-41.
22. Banerjee A, Mbamalu D, Hinchley G: The impact of process re-engineering on patient throughput in emergency departments in the UK. Int J Emerg Med 2008, 1(3):189-92.

23. Statens beredning för medicinsk utvärdering (SBU): Triage och flödesprocesser på akutmottagningen. En systematisk litteraturöversikt Stockholm; 2010, 197, ISBN 978-91-85413-33-1.

24. Eldridge S, Ashby D, Bennett C, Wakelin M, Feder G: Internal and external validity of cluster randomised trials: systematic review of recent trials. BMJ 2008, 336(7649):876-80.

25. Akobeng AK: Assessing the validity of clinical trials. J Pediatr Gastroenterol Nutr 2008, 47(3):277-82.

26. Guyatt GH, Oxman AD, Vist GE, Kunz R, Falck-Ytter Y, Alonso-Coello P, Schünemann HJ, GRADE Working Group: GRADE: an emerging consensus on rating quality of evidence and strength of recommendations. BMJ 2008, 336(7650):924-6.

27. Rogers T, Ross N, Spooner D: Evaluation of a 'See and Treat' pilot study introduced to an emergency department. Accid Emerg Nurs 2004, 12:24-7.

28. Fernandes $\mathrm{CM}$, Christenson JM, Price $\mathrm{A}$ : Continuous quality improvement reduces length of stay for fast-track patients in an emergency department. Acad Emerg Med 1996, 3:258-63.

29. Darrab AA, Fan J, Fernandes CM, Zimmerman R, Smith R, Worster A, Smith $T$, O'Connor $K$ : How does fast track affect quality of care in the emergency department? Eur J Emerg Med 2006, 13:32-5.

30. Kwa $P$, Blake D: Fast track: has it changed patient care in the emergency department? Emerg Med Australas 2008, 20:10-5.

31. Cooke MW, Wilson S, Pearson S: The effect of a separate stream for minor injuries on accident and emergency department waiting times. Emerg Med J 2002, 19:28-30.

32. Bond PA: A staffed ED assessment room: impact on wait times for nonurgent patients at a Saudi Arabian hospital. J Emerg Nurs 2001, 27:394-5.

33. Ardagh MW, Wells JE, Cooper K, Lyons R, Patterson R, O'Donovan P: Effect of a rapid assessment clinic on the waiting time to be seen by a doctor and the time spent in the department, for patients presenting to an urban emergency department: a controlled prospective trial. N Z Med J 2002, 115:U28.

34. Kilic YA, Agalar FA, Kunt M, Cakmakci M: Prospective, double-blind, comparative fast-tracking trial in an academic emergency department during a period of limited resources. Eur J Emerg Med 1998, 5:403-6.

35. O'Brien D, Williams A, Blondell K, Jelinek GA: Impact of streaming "fast track" emergency department patients. Aust Health Rev 2006, 30:525-32.

36. Sanchez M, Smally AJ, Grant RJ, Jacobs LM: Effects of a fast-track area on emergency department performance. J Emerg Med 2006, 31:117-20.

37. Rodi SW, Grau MV, Orsini CM: Evaluation of a fast track unit: alignment of resources and demand results in improved satisfaction and decreased length of stay for emergency department patients. Qual Manag Health Care 2006, 15:163-70.

38. leraci S, Digiusto E, Sonntag P, Dann L, Fox D: Streaming by case complexity: evaluation of a model for emergency department Fast Track. Emerg Med Australas 2008, 20:241-9.

39. Considine J, Kropman M, Kelly E, Winter C: Effect of emergency department fast track on emergency department length of stay: a casecontrol study. Emerg Med J 2008, 25:815-9.

40. Kelly AM, Bryant M, Cox L, Jolley D: Improving emergency department efficiency by patient streaming to outcomes-based teams. Aust Health Rev 2007, 31:16-21.

41. King DL, Ben-Tovim DI, Bassham J: Redesigning emergency department patient flows: application of Lean Thinking to health care. Emerg Med Australas 2006, 18:391-7.

42. Patel PB, Vinson DR: Team assignment system: expediting emergency department care. Ann Emerg Med 2005, 46:499-506.

43. Holroyd BR, Bullard MJ, Latoszek K, Gordon D, Allen S, Tam S, Blitz S, Yoon P, Rowe BH: Impact of a triage liaison physician on emergency department overcrowding and throughput: a randomized controlled trial. Acad Emerg Med 2007, 14:702-8.

44. Subash F, Dunn F, McNicholl B, Marlow J: Team triage improves emergency department efficiency. Emerg Med J 2004, 21:542-4.

45. Travers JP, Lee FC: Avoiding prolonged waiting time during busy periods in the emergency department: Is there a role for the senior emergency physician in triage? Eur J Emerg Med 2006, 13:342-8. 
46. Richardson JR, Braitberg G, Yeoh MJ: Multidisciplinary assessment at triage: a new way forward. Emerg Med Australas 2004, 16:41-6.

47. Partovi SN, Nelson BK, Bryan ED, Walsh MJ: Faculty triage shortens emergency department length of stay. Acad Emerg Med 2001, 8:990-5.

48. Grant S, Spain D, Green D: Rapid assessment team reduces waiting time. Emerg Med 1999, 11:72-77.

49. Kendall J, Reeves B, Clancy M: Point of care testing: randomised controlled trial of clinical outcome. BMJ 1998, 316:1052-7.

50. Murray RP, Leroux M, Sabga E, Palatnick W, Ludwig L: Effect of point of care testing on length of stay in an adult emergency department. $J$ Emerg Med 1999, 17:811-4.

51. Lee-Lewandrowski E, Corboy D, Lewandrowski K, Sinclair J, McDermot S, Benzer TI: Implementation of a point-of-care satellite laboratory in the emergency department of an academic medical center. Impact on test turnaround time and patient emergency department length of stay. Arch Pathol Lab Med 2003, 127:456-60

52. Parvin CA, Lo SF, Deuser SM, Weaver LG, Lewis LM, Scott MG: Impact of point-of-care testing on patients' length of stay in a large emergency department. Clin Chem 1996, 42:711-7.

53. Tsai WW, Nash DB, Seamonds B, Weir GJ: Point-of-care versus central laboratory testing: an economic analysis in an academic medical center. Clin Ther 1994, 16:898-910.

54. Singer AJ, Viccellio P, Thode HC Jr, Bock JL, Henry MC: Introduction of a stat laboratory reduces emergency department length of stay. Acad Emerg Med 2008, 15:324-8.

55. Lindley-Jones M, Finlayson BJ: Triage nurse requested $\mathrm{x}$ rays-are they worthwhile? J Accid Emerg Med 2000, 17:103-7.

56. Parris W, McCarthy S, Kelly AM, Richardson S: Do triage nurse-initiated Xrays for limb injuries reduce patient transit time? Accid Emerg Nurs 1997, 5:14-5.

57. Thurston J, Field S: Should accident and emergency nurses request radiographs? Results of a multicentre evaluation. J Accident \& Emerg Med 1996, 13:86-9.

58. Karpiel M, Williams ME: Developing a fast track program. J Amb Care Manage 1998, 2:35-48.

59. Sjönell G: Effect of establishing a primary health care centre on the utilization of primary health care and other out-patient care in a Swedish urban area. Fam Pract 1986, 3:148-54.

60. Washington DL, Stevens CD, Shekelle PG, Baker DW, Fink A, Brook RH: Safely directing patients to appropriate levels of care: Guideline-driven triage in the emergency service. Ann Emerg Med 2000, 36:15-22.

61. Derlet RW, Kinser D, Ray L, Hamilton B, McKenzie J: Prospective identification and triage on nonemergency patients out of an emergency department: A five-year study. Ann Emerg Med 1995 25:215-23.

62. Lowe RA, Bindman $A B$, Ulrich SK: Refusing care to emergency department patients: evaluation of published triage guidelines. Ann Emerg Med 1994, 23:286-93

63. Widgren BR, Jourak M: Medical Emergency Triage and Treatment System (METTS): A new protocol in primary triage and secondary priority decision in emergency medicine. $J$ Emerg Med 2008.

64. Nordberg M, Castrén M: The validity of the triage system ADAPT. Scand J Trauma Resus Emerg Med 2010, 18(Suppl 1):36.

65. Askenasi R, Lheureux PE, Gillet JB: Infuence of tests on patient time in the emergency department. Reanimation Soins Intensifs Medecine d'Urgency 1989, 5:201-2.

66. Schimke I: Quality and timeliness in medical laboratory testing. Anal Bioanal Chem 2009, 393:1499-504.

67. Kollberg B, Dahlgaard J, Brehmer P-O: Measuring lean initiatives in health care services: issues and findings. Int J Productivity \& Performance Management 2007, 56:7-24.

doi:10.1186/1757-7241-19-43

Cite this article as: Oredsson et al: A systematic review of triage-related interventions to improve patient flow in emergency departments. Scandinavian Journal of Trauma, Resuscitation and Emergency Medicine 2011 19:43.

\section{Submit your next manuscript to BioMed Central and take full advantage of:}

- Convenient online submission

- Thorough peer review

- No space constraints or color figure charges

- Immediate publication on acceptance

- Inclusion in PubMed, CAS, Scopus and Google Scholar

- Research which is freely available for redistribution

Submit your manuscript at www.biomedcentral.com/submit
Ciomed Central 